\title{
Influence of Bioethanol Blends on Performances of a Micro Turbojet Engine
}

\author{
GRIGORE CICAN ${ }^{1}$, MARIUS DEACONU ${ }^{2}$, RADU MIREA $^{2 *}$, ANDREI TIBERIU CUCURUZ ${ }^{3}$ \\ ${ }^{1}$ University Politehnica of Bucharest, Faculty of Aerospace Engineering, 1-7 Polizu Str., 011061, Bucharest, Romania \\ ${ }^{2}$ Romanian Research and Development Institute for Gas Turbines - COMOTI, 220 D Iuliu Maniu Av., 061126, Bucharest, \\ Romania
}

${ }^{3}$ SC Cromatec Plus SRL, 1 Petre Ispirescu Str., 077167, Snagov, Romania

\begin{abstract}
This paper proposes a study regarding the use of bioethanol as fuel for turbine engines used in aviation. For this purpose, three blends of 5, 10, and 15\% concentrations of bioethanol mixed with Jet A fuel were tested on JET CAT P80 microturbo engine. During the engine testing, the following parameters were monitored: engine speed, generated force, temperature in front of the turbine, fuel volumetric flow rate, and vibration levels measured both on axial and radial direction. The tests were performed by maintaining the microturbo engine for about 1 min at three operating regimes: idle, cruise, and maximum speed. In addition, a comparative analysis between fuels for a test with the microturbo engine from the idle position to maximum position is presented. After the tests were conducted, a jet engine cycle analysis was performed at the max regime and the fuel specific consumption, the efficiency of the combustion chamber, and the thermal efficiency of the engine for each fuel blend were calculated. The tests were made without making any modifications to the engine components or automation system.
\end{abstract}

Keywords: bioethanol, Jet A fuel, micro turbojet, fuel specific consumption, thermal efficiency

\section{Introduction}

An important issue for our society is related to the chemical pollution generated especially by the burning of fossil fuels [1]. Among the main fossil fuel consumers, it is well known that aviation industry consumes very large amounts of fossil fuel [2], which inevitably sometime will be ended. There are many studies regarding the harmful effects of the fuel burning. Therefore, intense policies were developed to replace the crude oil with other sustainable fuel types for thermal engines, especially in the field of aviation, in order to diminish the chemical pollution $[3,4]$. The main policy is the directive for the development of new aviation fuels, e.g., biodiesel, ethanol, and bioethanol [5-7]. In the automotive industry, ethanol and bioethanol are widely used in piston engines by using the E85 [8]. Bioethanol produced by alcoholic fermentation of various feedstocks, e.g., energy crops, agroindustrial wastes, algal biomass, is a valuable source of energy and materials [9-13].

Many experiments focus on the biodiesel use in turbine engines [14,15]. There are also studies related by the use of alcohols in turbine engines [16-19]. A problem that ethanol/bioethanol can solve is related to the decrease in the amount of pollutants produced by combustion. For a long time the ethanol has been considered an important alternative fuel for engines because it solves a number of problems of traditional crude fuels such as emission of greenhouse gases and particles.

The purpose of this paper is to analyze experimentally the possibility of using the blends of bioethanol with Jet A fuel in turbine engines. Burning tests were performed by using the blends as fuel for the Jet Cat P80 microturbo engine, which is found in the Engine Laboratory from the Aerospace Engineering Faculty, University Politehnica of Bucharest. According to the technical manual of the turbo engine, 5\% Aeroshell oil must be introduced in the fuel in order to ensure the bearing lubrication. As was specified, the burning tests were performed using four blends of fuels: the first fuel is represented by the recommended fuel by the manufacturer (Jet A 95\% with 5\% Aeroshell oil) and other three blends of Jet A with bioethanol, i.e., Jet A 90\% with 5\% Aeroshell oil and 5\% bioethanol, Jet A $85 \%$ with 5\% Aeroshell oil and 10\% bioethanol, and Jet A 80\% with 5\% Aeroshell oil and 15\% bioethanol.

\footnotetext{
*email: radu.mirea@comoti.ro
} 
The microturbo engine running on bioethanol was analyzed in terms of vibration levels measured both on axial and radial direction. Also, a comparative analysis between fuels for a test with the microturbo engine from the idle position to maximum position is presented. After the tests were conducted, a jet engine cycle analysis was performed at the maximum regime and the specific consumption, the efficiency of the combustion chamber, and the thermal efficiency of the engine for each fuel blend were determined.

The benefits of using these fuel mixtures based on alcohols and especially on bioethanol are that they reduce pollutants and do not require engine modifications. The major disadvantage is that the bioethanol has an inferior calorific power, much lower than that of Jet A kerosene and therefore the fuel specific consumption is higher [20].

\section{Materials and methods}

A schematic view of the work performed in this study is presented in Figure 1. The first step was to determine the density of each fuel. Fuel mass flow rate $[\mathrm{kg} / \mathrm{s}]$ was determined based on its density and volumetric flow rate $[\mathrm{L} / \mathrm{s}]$.

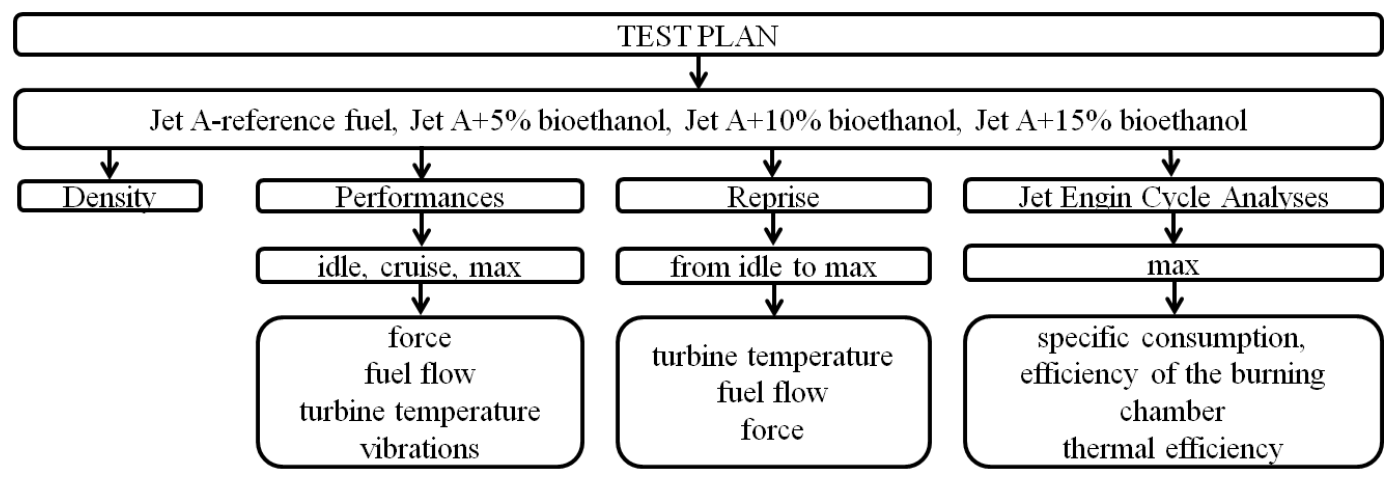

Figure 1. Measurement plan

The monitored turbo engine performances were: the speed [rpm], generated force $F[\mathrm{~N}]$, the temperature in front of the turbine $T_{3}\left[{ }^{\circ} \mathrm{C}\right]$, and the fuel volumetric flow rate $Q_{c}[\mathrm{~L} / \mathrm{s}]$. The tests were done by holding the micro turboengine for about $1 \mathrm{~min}$ at idle speed, at cruise speed, and at maximum speed. The tests were made without making any modifications to the components or its automation.

The tests were performed using a Jet CAT P80 micro turboengine. The Jet CAT P80 [21] micro engine and the test bench are presented in Figure 2.

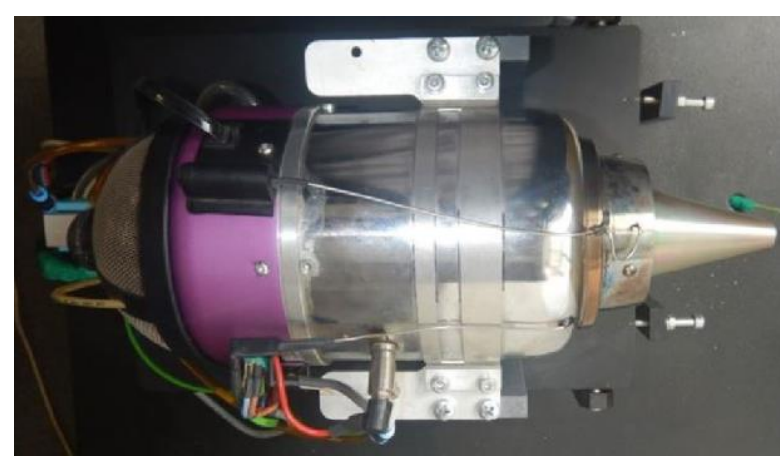

Figure 2. Jet CAT P80 test bench

As is stated above, the first objective is to determine the density of each blend with bioethanol.

The second objective of these measurements was to monitor the performances of the Jet Cat P80 analyzing different parameters: propulsion force, fuel flow, temperature in front of turbine, and vibration level. In this study no modifications were made on the engine (injectors) and also neither on 
automation panel, the fuel flow rate being automatically adjusted by the automation. Four fuels were tested, Jet A (reference fuel), Jet A+5\% bioethanol, Jet A $+10 \%$ bioethanol, Jet A $+15 \%$ bioethanol (Figure 3).

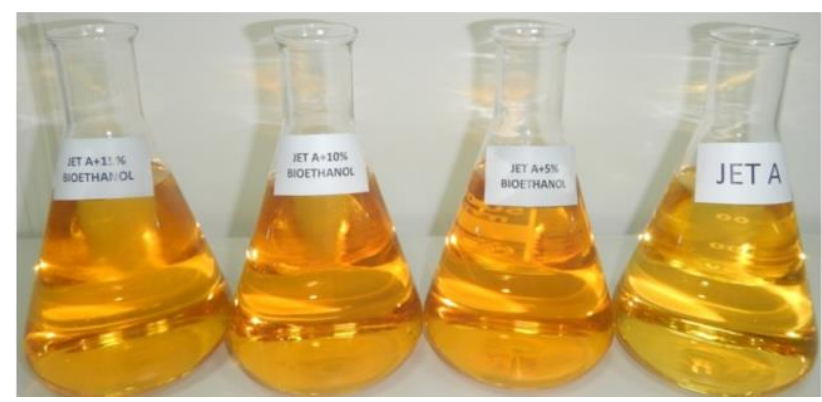

Figure 3. Fuel blends

The testing has been performed for the most important regimes of a turbo engine: idle, cruise, and maximum speed. Each regime corresponds to a percent from the throttle, i.e., idle corresponds to $18.7 \%$, cruise to $30 \%$, and maximum to $94 \%$ (not to exceed the safety speed). The engine has been running for $1 \mathrm{~min}$ for each regime.

The vibrations were monitored by using two accelerometers PCB 352C03 mounted on axial and radial direction. Because of turbo engine small dimension and impossibility of mounting the transducers close to the bearing, these were screwed into the micro-engine support as is presented in Figure 4.

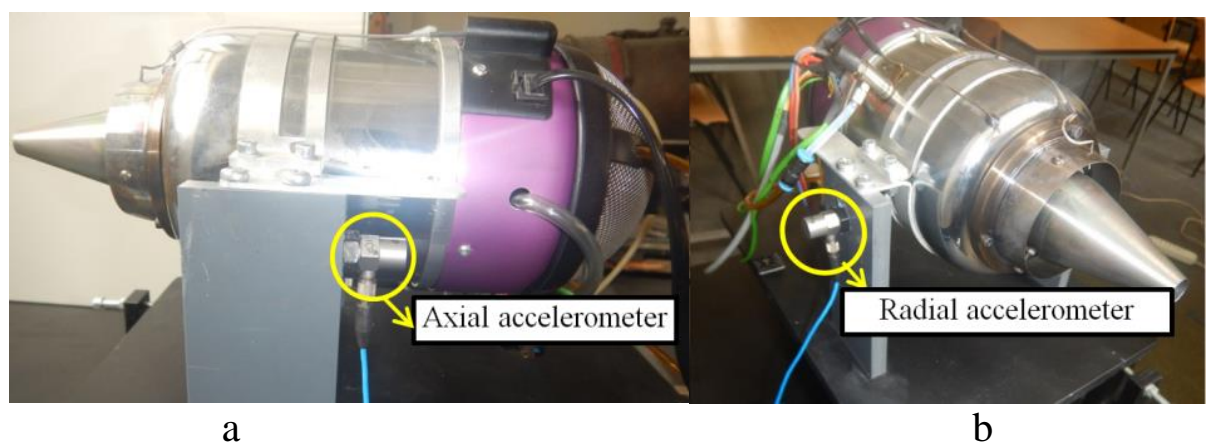

Figure 4. Axial accelerometer (a) and radial accelerometer (b)

Using the bioethanol fuel in micro-engine can lead to a change of the burning flame leading to flame instability, that can be observed in vibration measurement were this instability can produce low vibration frequencies. An increase or a decrease in burning turbulence can lead to a change of the vibration levels. For this reason the vibration were measured on two directions.

The third objective of the experimental study was to monitor the stability of the transient regimes by using four blends. This transient stability was determined by performing a run up test from the idle to maximum regime.

The fourth objective was to perform a jet engine cycle analysis at the maximum functioning regime of the engine.

\section{Results and discussions \\ Density of the fuel blends}

The physical and chemical properties of the bioethanol can heavily influence the combustion process, the engine performances, and the efficiency of the engine. Bio-ethanol is a colourless liquid with specific odour. Physical and chemical properties of bio-ethanol and Jet A fuel are detailed in the related literature [22]. 
To determine bioethanol density, laboratory tests were performed at Physical and Chemical Testing Laboratory of COMOTI (Figure 5) according to a recommended procedure [23]. The data presented in table 1 highlight that the blend density decreases as the bioethanol concentration increases.

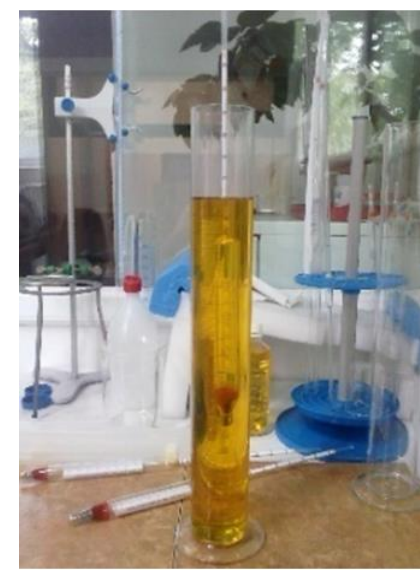

Figure 5. Density measurements

Table 1. Density of fuel blends

\begin{tabular}{|c|c|}
\hline Type of fuel blends & Density $\left[\mathrm{kg} / \mathrm{m}^{3}\right]$ \\
\hline Jet A & 817 \\
\hline Jet A+5\% bioethanol & 815 \\
\hline Jet A+10\% bioethanol & 813 \\
\hline Jet A+15\% bioethanol & 812 \\
\hline
\end{tabular}

\section{Evaluation of experimental performances}

In a first stage of the experimental performance evaluation of micro turbojet engine, the tests were performed with the engine functioning at constant regimes: idle, cruise, and maximum ( 1 min for each fuel blend).

First, the temperature in front of the turbine $T_{3}\left[{ }^{\circ} \mathrm{C}\right]$ was monitored for the three regimes, the results being presented in Figure 6.The tests highlight that the temperature in front of the turbine is lower for the three blends than for Jet A. This is explained by the lower calorific value of bioethanol. It can be noticed that the most pronounced temperature drop is obtained for cruise mode. The temperature decreases by increasing the concentration of bioethanol. Although the temperature is smaller, it does not fall below the engine operating limit for the three studied bioethanol combinations.

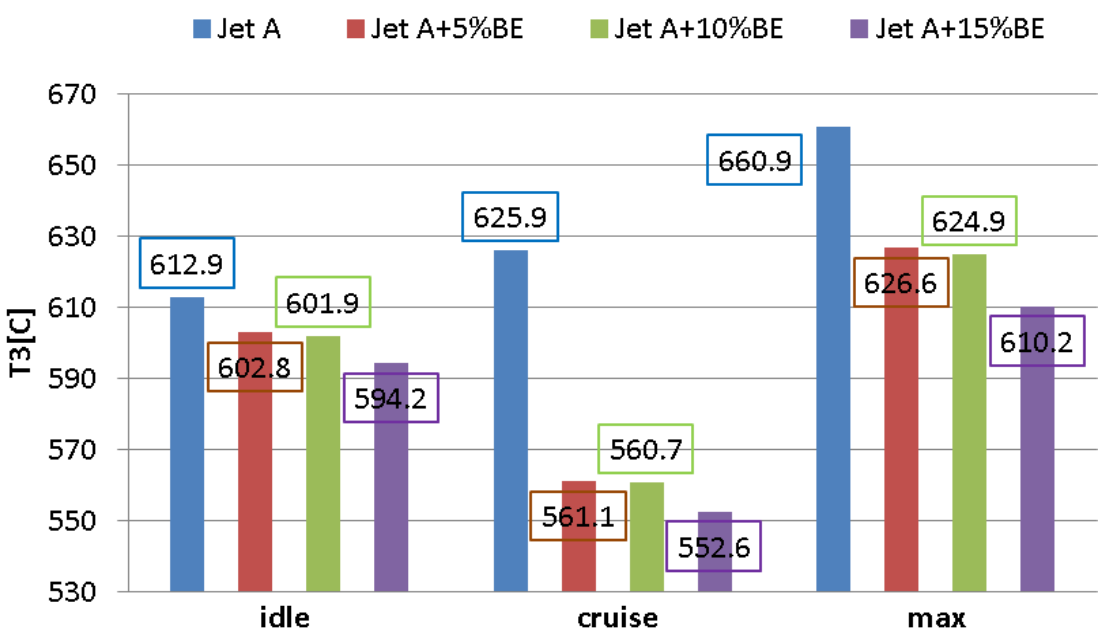

Figure 6. Variation of $T_{3}\left[{ }^{\circ} \mathrm{C}\right](\mathrm{BE}$ - bioethanol) 
Variation of fuel volumetric flow rate $Q_{c}[\mathrm{~L} / \mathrm{h}]$ is presented in Figure 7. The $Q_{c}$ variations between reference fuel, Jet $\mathrm{A}$, and the 3 blends are relative small and the engine automation adjusted the fuel flow so that the engine speed remains constant. Also it can be observed that the volumetric flow rate increases by increasing the bioethanol concentration in the blends.

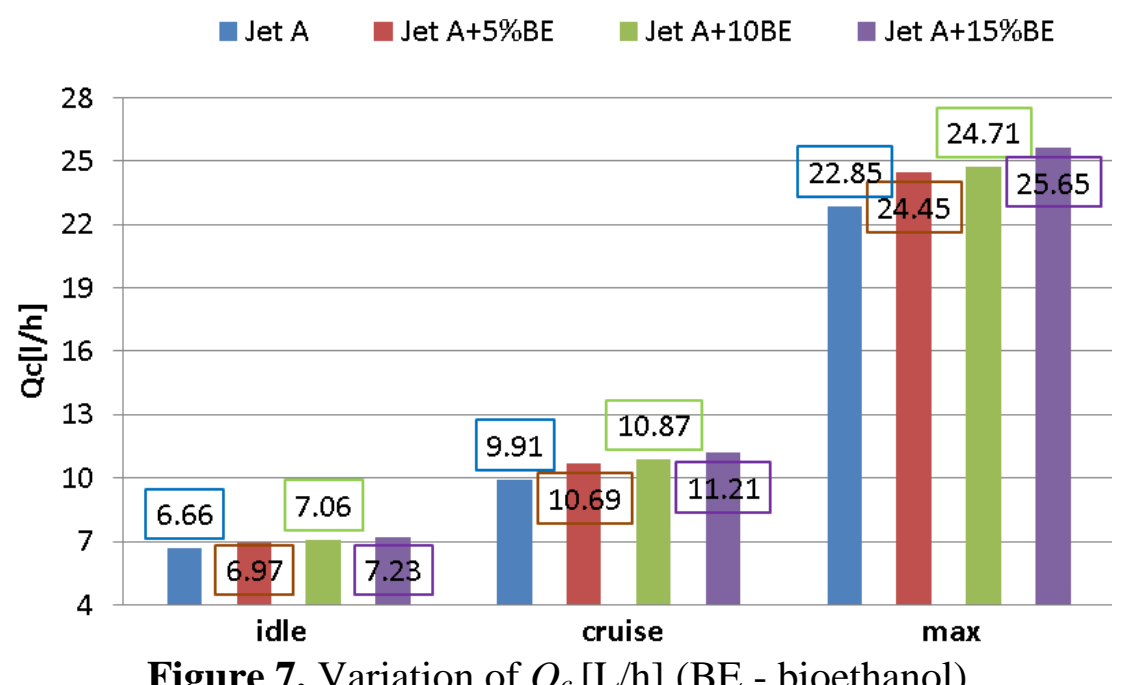

Variation of force $F[\mathrm{~N}]$ is presented in Figure 8.It can be observed that the measured force slightly increases with the increase in bioethanol concentration of fuel for all three studied regimes. It is known from the theory [24] the fact that if the temperature in front of the turbine is decreased, the exhaust speed is reduced, leading to a drop of the engine force. In this particular case of using bioethanol and Jet A blends, this fact is not confirming, due to the engine's automatic which maintains a constant speed, leading to an increase in fuel flow rate and intake air flow rate, determining an increase in engine force.

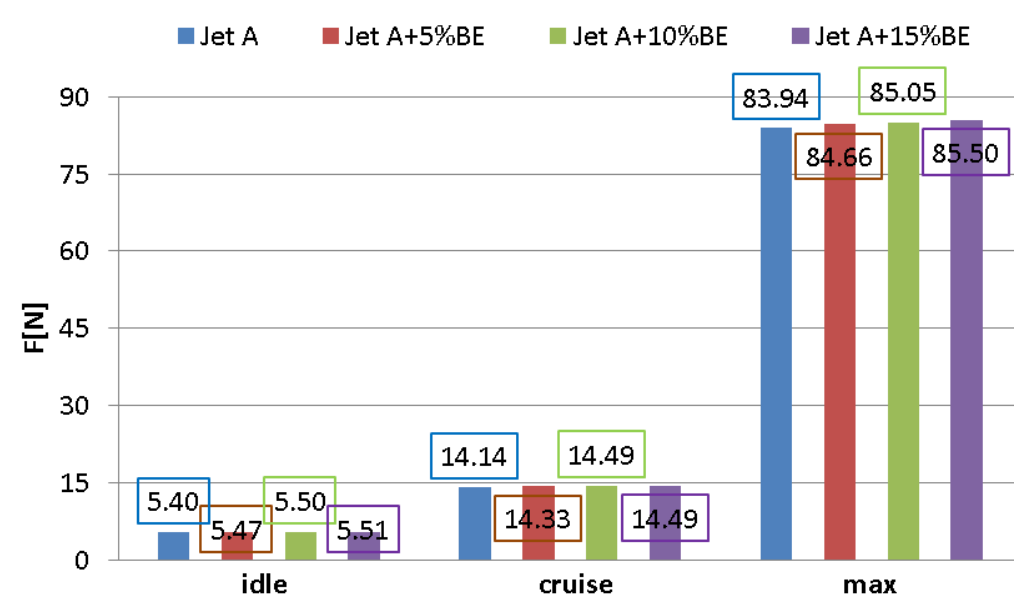

Figure 8. Variation of force $F[\mathrm{~N}](\mathrm{BE}$ - bioethanol)

The stability of the engine was analyzed also from the vibration point of view, the measurement results being presented in Figure 9. Vibration spectrum analysis corresponding to the maximum regime is presented in figure 10. The differences between the overall vibrations levels measured for each blend are small. The maximum acceleration was obtained for the Jet A fuel and the lowest vibration for the blend with $15 \%$ bioethanol, as can be seen from Figure 10. The vibration spectrum confirms the operation stability by the small differences between them. The single important difference in spectra is observed at compressor Blade Pass Frequency (BPF) component, which is presented in the zoomed 
window. During the Jet A fuel testing, the engine had a lower speed than for the other fuels. The speed differences between the Jet A fuel and its blends are around 76 RPM.

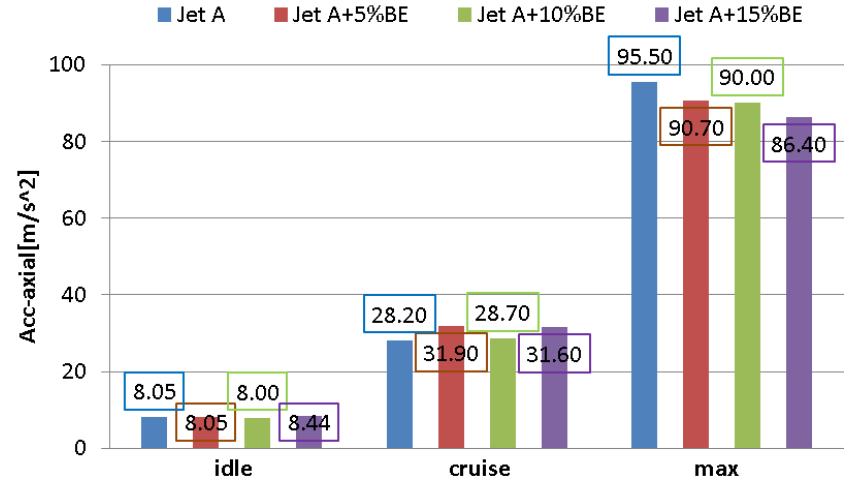

a

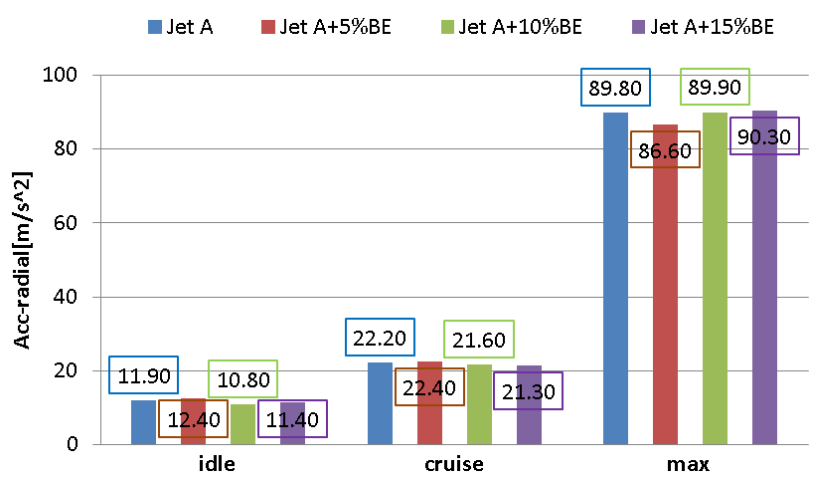

$\mathrm{b}$

Figure 9. Vibration levels: (a) axial and (b) radial (BE - bioethanol)

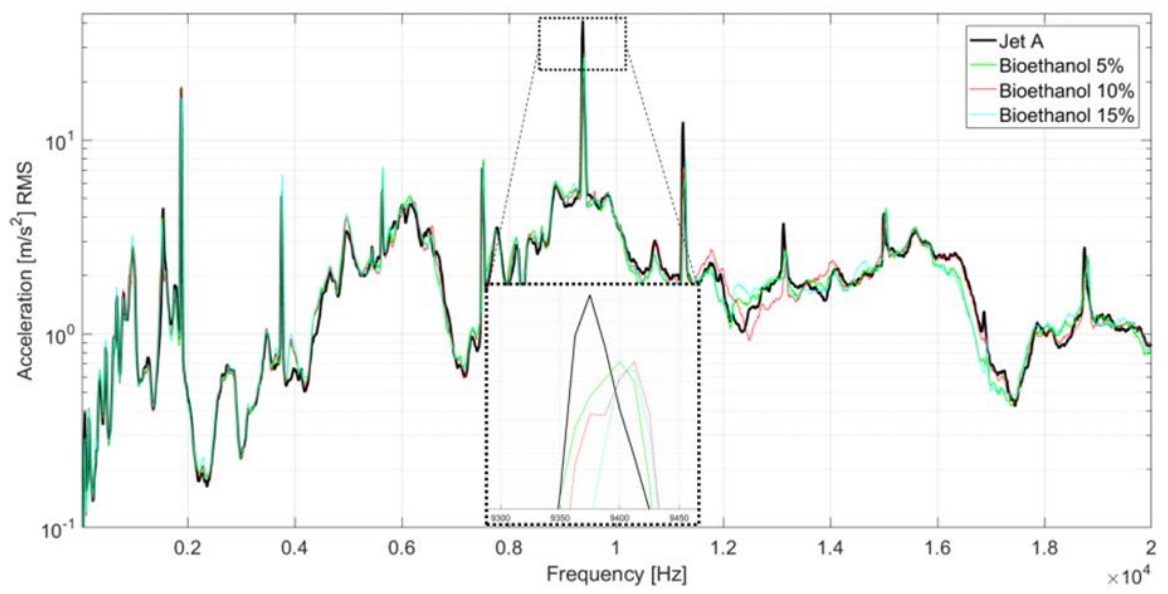

Figure 10. Vibration spectrum for maximum regime

The parameters analysis during the tests is presented in Table 2 where it can be observed the variation of the main parameters compared to the reference fuel.

Table 2. Measured parameters

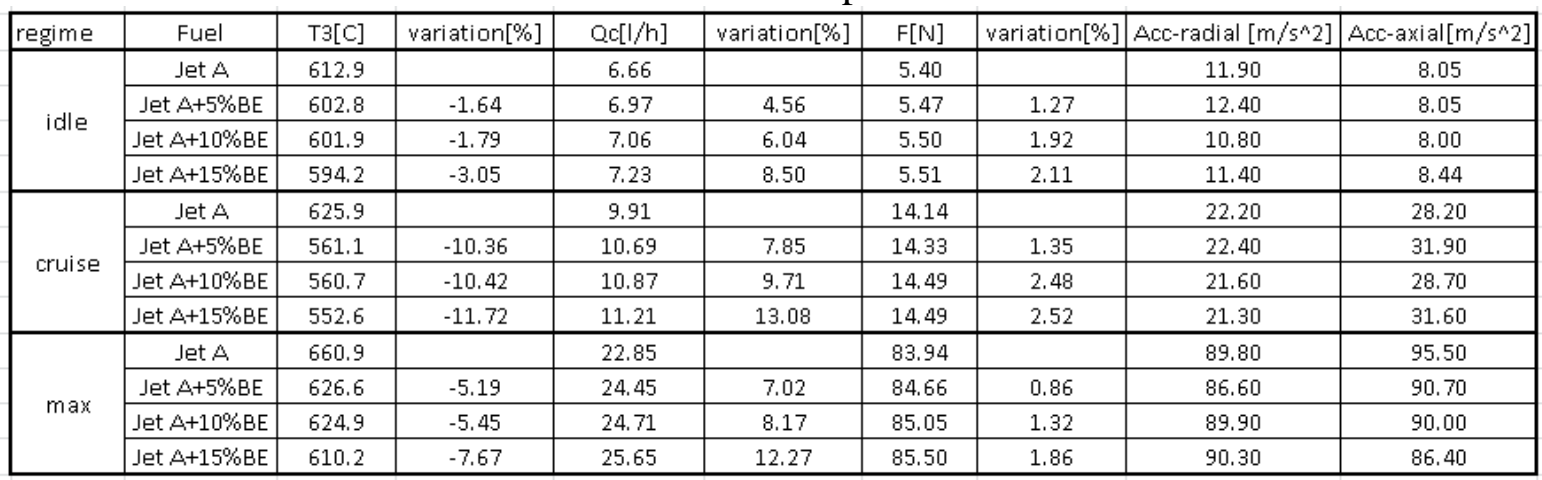

\section{Experimental reprise}

This stage of the experimental performance evaluation of micro turbojet engine consisted in studying a transient regime where the engine was accelerated from idle to maximum passing through all operating regimes. After performing a run-up test from idle to a speed close to the maximum speed, the results shown in Figure 11 highlighted that the temperature in the front of the turbine T3 has the 
same pattern for the all blends, but having lower values than the Jet A without jeopardizing the engine operation. Also the fuel volumetric flow rate increases with an increase in engine speed and bioethanol concentration over the whole range of tested speeds (Figure 12). For a better visualization and understanding of the analyzed parameters, in Figure 13 the force depending to the fuel volumetric flow rate is plotted. Depicted data emphasize that the propulsion force increases with the fuel volumetric flow rate. Another aspect is that the force decreases as a higher concentration of bioethanol is used for all fuel flows. Analyzing the transient processes we can see the continuous variation of the studied parameters and that they fall within the functionality limits of the engine.

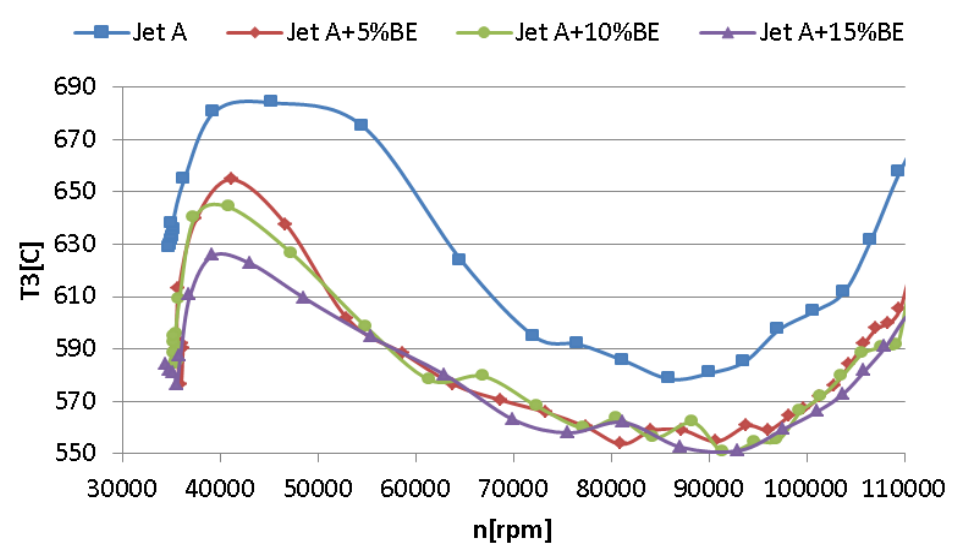

Figure 11. $T_{3}$ variation from idle to maximum depending on the engine speed (BE - bioethanol)

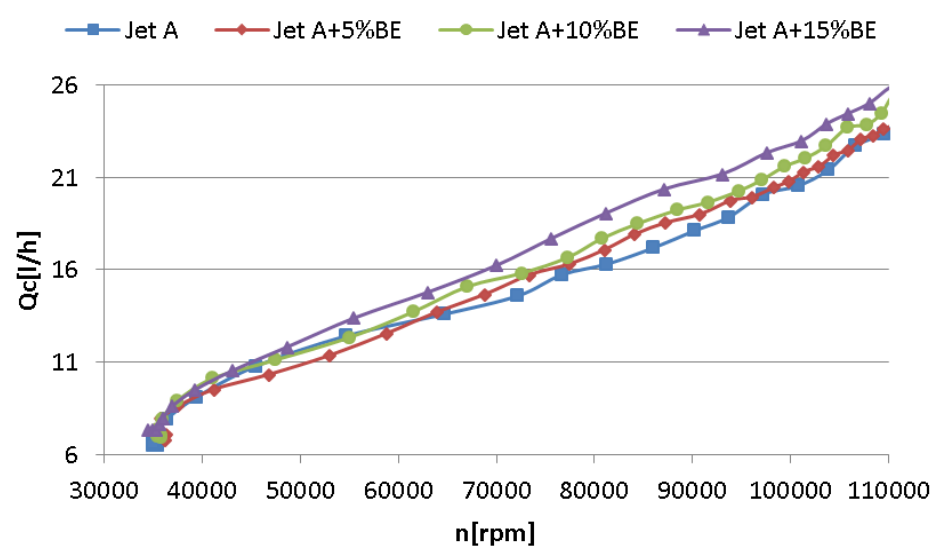

Figure 12. Fuel consumption variation from idle to maximum depending on the engine speed (BE - bioethanol)

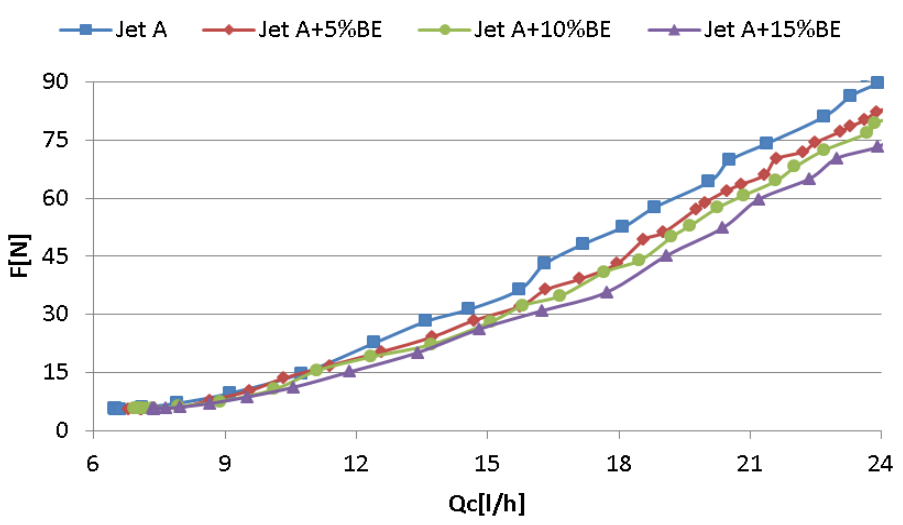

Figure 13. Force variation from idle to maximum depending on the fuel consumption (BE - bioethanol 


\section{Jet engine cycle analysis}

Jet engine cycle analysis was applied to determine characteristic micro engine performances of the maximum regime, i.e., the fuel specific consumption, the efficiency of the burning chamber, and the thermal efficiency of the engine for fuel blends [25]. The fuel specific consumption, $C_{s p}[\mathrm{~kg} / \mathrm{Nh}]$, was calculated based on Eqs. (1)-(3), where $F_{s t}[\mathrm{~m} / \mathrm{s}]$ is the specific thrust, $F[\mathrm{~N}]$ the thrust (force), $\dot{M}_{c}$ $[\mathrm{kg} / \mathrm{s}]$ the fuel mass flow rate, $\dot{M}_{a}[\mathrm{~kg} / \mathrm{s}]$ the air mass flow rate, $f$ the fuel-air mass ratio, $F H V[\mathrm{~J} / \mathrm{kg}]$ the fuel heating value, $c_{p}[\mathrm{~J} / \mathrm{kgK}]$ the specific heat capacity, $T_{2}\left[{ }^{\circ} \mathrm{C}\right]$ the temperature in front of combustor chamber, and $T_{3}\left[{ }^{\circ} \mathrm{C}\right]$ the temperature in front of turbine. The fuel specific consumption (Figure 14) increases due to a bigger concentration of bioethanol, this was expected due to the lower calorific power of the bioethanol.

$$
\begin{aligned}
& F_{s t}=\frac{F}{\dot{M}_{c}+\dot{M}_{a}} \\
& f=\frac{\dot{M}_{c}}{\dot{M}_{a}}=\frac{1}{F H V}\left(c_{p 3} T_{3}-c_{p 2} T_{2}\right) \\
& C_{s p}=3600 \frac{f}{F_{s t}}
\end{aligned}
$$

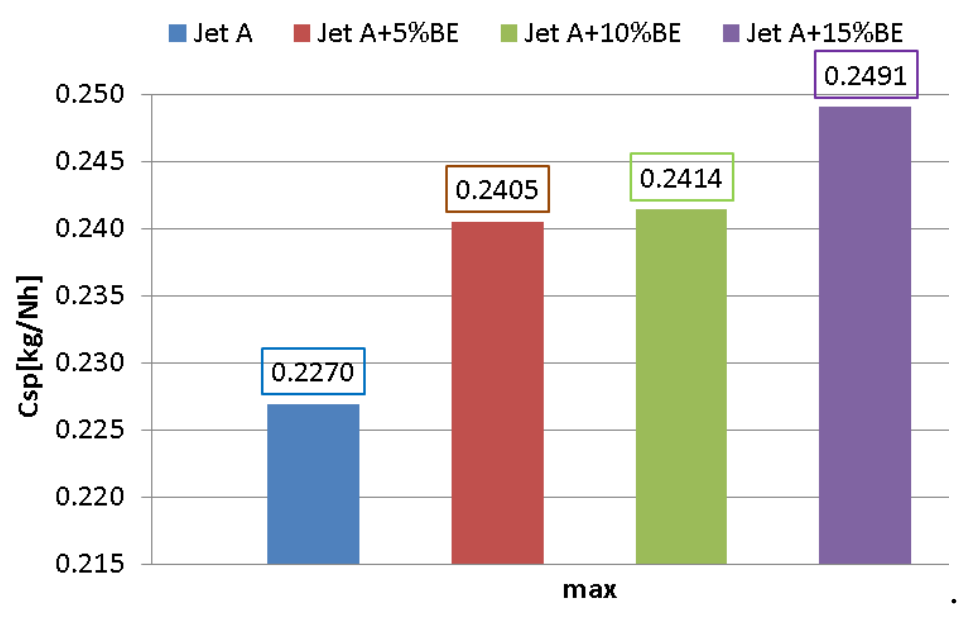

Figure 14. Variation of fuel specific consumption

$$
C_{s p}[\mathrm{~kg} / \mathrm{Nh}](\mathrm{BE}-\text { bioethanol) }
$$

The efficiency of the burning chamber, $\eta_{b}$, was estimated by Eq. (4) andthe thermal efficiency of the engine, $\eta_{T}$, was calculated using Eq. (5), where $v_{e}[\mathrm{~m} / \mathrm{s}]$ is the gas velocity from the nozzle.

$$
\begin{aligned}
& \eta_{b}=\frac{\left(\dot{M}_{c}+\dot{M}_{a}\right) c_{p 3} T_{3}-\dot{M}_{a} c_{p 2} T_{2}}{\dot{M}_{c} F H V}=\frac{(1+f) c_{p 3} T_{3}-c_{p 2} T_{2}}{f F H V} \\
& \eta_{T}=\frac{(1+f)}{2 f} \frac{v_{e}^{2}}{F H V}=\frac{(1+f)}{2 f} \frac{F_{s t}^{2}}{F H V}
\end{aligned}
$$

Taking into account that in each mixture 5\% Aeroshell 500 oil was added, the fuel heating value of each fuel blend, $F H V$ [J/kg], was determined using Eq. (6), where $g$ is the mass fraction of each compound in the blend.

$$
F H V=g_{\text {Aeroshell500 }} F H V_{\text {Aeroshell500 }}+g_{\text {jetA }} F H V_{\text {JetA }}+g_{\text {bioethanot }} F H V_{\text {bioethanol }}
$$


Characteristic performances of maximum regime in terms of fuel-air mass ratio, efficiency of the burning chamber, and thermal efficiency of the engine are presented in Table 3 Tabulated data indicate that the fuel heating value and the burning efficiency of the combustion chamber decrease as the bioethanol concentration increases, whereas engine thermal efficiency varies almost insignificantly.

Table 3. Calculated performances for the maximum regime

\begin{tabular}{|c|c|c|c|}
\hline Type of fuel blends & $F H V[\mathrm{~kJ} / \mathrm{kg}]$ & $\eta_{b}[\%]$ & $\eta_{T}[\%]$ \\
\hline Jet A & 40660 & 87.5 & 6.47 \\
\hline Jet+5\% bioethanol & 39900 & 79.0 & 6.27 \\
\hline Jet+10\% bioethanol & 39140 & 79.7 & 6.40 \\
\hline Jet+15\% bioethanol & 38380 & 76.4 & 6.37 \\
\hline
\end{tabular}

\section{Conclusions}

Studies in the related literature revealed that the use of ethanol especially bioethanol reduces the emissions resulted from the burning process of the fossil fuels.

The results obtained in this study highlight that bioethanol, in the studied proportions, could be considered a stable alternative fuel for turbine engines without making technological and functional modifications of the engine. It was observed that at all the three studied regimes, idle, cruise, and maximum, the engine has a stable operation without jeopardizing its integrity.

Due to the low calorific power of the bioethanol, the temperature in front of turbine decreases without exceeding the functionality temperature limits. By lowering the released temperature from burning, implicitly resulting lower temperature in front of turbine, the mechanical work produced by the turbine decreases leading to a decrease in the burning gases speed and in the propulsion force.

The analysis of the fuel consumption performed by using the temperature drop in the front of the turbine highlighted an increase in the fuel consumption with increasing concentration of the bioethanol. Fuel consumption increases with bioethanol concentration increasing, leading to a higher propulsion force, where an increase of $2.52 \%$ was obtained for $15 \%$ bioethanol.

The vibration levels during the bioethanol test did not exceed the levels when the JET A was tested. On axial direction vibration with bioethanol were lower than with JetA.

From the run-up test performed from idle to maximum speed (Figures 11-13) it is observed that the engine operates in functional parameters, without having temperature problems.

The jet engine cycle analysis performed at maximum regime, shown that a higher concentration of bioethanol in fuel lead to decrease of the specific consumption and it can be concluded that the thermal efficiency of the engine does not show any major variation for the four types of fuel and the burning efficiency of the burning chamber decreases as the bioethanol concentration increases.

Another advantage is represented by the stable operation without vibrations and parameter variations, these being obtained without a technological change to the engine. From the vibration point of view, the bioethanol used as fuel has led to lower vibration levels.

As a future work, it is proposed to study the pollutant level, the engine operation under different atmospheric conditions with negative environmental temperature, normal temperature, and very high temperature. Other studies related to the transient regimes can be conducted, where a very fast acceleration can be performed to determine the engine stability from the temperature point of view, to not exceed the temperature limits supported by the power turbine.

Acknowledgements: This work was carried out within POC-A1-A1.2.3-G-2015, ID/SMIS code: P_40_422/105884, “TRANSCUMAT" Project, Grant no. 114/09.09.2016 (Subsidiary Contract no. 1/D.1.5/114/24.10.2017), Project supported by the Romanian Minister of Research and Innovation.

\section{References}

1.***BP Statistical Review of World Energy, 2017, https://www.bp.com/en/global/corporate/energyeconomics/statistical-review-of-world-energy.html. 
2.***OPEC, Annual Statistical Bulletin of Organization of the Petroleum Exporting Countries, 2017, https://www.opec.org/opec_web/static_files_project/media/downloads/publications/ASB2017_130620 17.pdf.

3.***Flight Path 2050, Europe's Vision for Aviation, Report of the High Level Group on Aviation Research, Publications Office of the European Union, Luxembourg, 2011.

4.WINCHESTER, N., MALINA, R., STAPLES, M., BARRETT, S., Energy Economics, 49, 2015, p. 482.

5.BLAKEY, S., RYE, L., WILSON, C.W., Proceedings of the Combustion Institute, 33, 2011, p. 2863. 6.HARI, T.K., YAAKOB, Z., BINITHA, N.N., Renewable and Sustainable Energy Reviews, 42, 2015, p. 1234.

7.SAVEL'EV, A.M., SKIBIN, V.A., STARIK, A.M. Evaluation of emission characteristics of gas turbine engines using alternative fuels, $29^{\text {th }}$ Congress of the International Council of the Aeronautical Sciences, St. Petersburg, Russia, 2014.

8.BIELACZYC, P., WOODBURN, J., GANDYK, M., SZCZOTKA, A., Combustion Engines, 166, 2016, p. 39.

9.ALKIMIM, A., CLARKE, K., Land Use Policy, 72, 2018, p. 65.

10.CIOROIU, D.R., PARVUlESCU, O.C., KONCSAG, C.I., DOBRE, T., RADUCANU, C., Rev. Chim., 68(10), 2017, 2311.

11.ERSHOV, M.A., GRIGOREVA, E.V., HABIBULLIN, I.F., EMELYANOV, V.E., STREKALINA, D.M., Renewable and Sustainable Energy Reviews, 66, 2016, p. 228.

12.TIRPAN, D.R.C., KONCSAG, C.I., CIUFU, A.G., PARVUlESCU, O.C., DOBRE, T., Cell. Chem. Technol., 53, nos. 3-4, 2019, p. 341.

13.TRICA, B., PARVUleSCU, O.C., DOBRE, T., Al JANABI, A.A.A., RADUCANU, C., PATRICHI, C., Rev. Chim., 68, (11), 2017, 2708.

14.ABU TALIB, A.R., GIRES, E., AHMAD, M.T., Journal of Fuels, Article ID 946485, 2014, p. 1.

15.NOURELDIN, I.M. HAMZA, A.A., OOKAWARA, S., Performance assessment of turbojet engine operated with alternative biodiesel, Proceedings of the ASME Power Conference, Boston, Massachusetts, USA, 2013.

16.LITT, J., CHIN, J., LIU, Y., Simulating the Use of Alternative Fuels in a Turbofan Engine, NASA/TM - 2013-216547, 2013.

17.BORGES DA COSTA, B., MARTINS, C., LACAVA, P.T., Ethanol utilization in the get-58 turbine applied to electric power generation, $20^{\text {th }}$ International Congress of Mechanical Engineering ABCM, Gramado, RS, Brazil, 2009.

18.MOLIERE, M., VIERLING, M., ABOUJAIB, M., PATIL, P., ERANKI, A., CAMPBELL, A., TRIVEDI, R., NAINANI, A, ROY, S., PANDEY, N., Gas turbines in alternative fuel applications: bio-ethanol field test, Proceedings of GT 2009 ASME Turbo Expo, Power for Land, Sea and Air Orlando, FL USA, 2009.

19.MENDEZ, C.J., PARTHASARATHY, R.N.,GOLLAHALLI, S.R., Applied. Energy, 118, 2014, p. 135.

20.CHUCK, C., DONNELLY, J., Applied Energy, 118, 2014, p. 83.

21.***US. Patent 6216440, Jet Cat instruction manual, 2008.

22.***Handbook of aviation fuel properties, Coordinating Research Council, $3^{\text {rd }}$ edition, 2004.

23.***SR EN ISO 3675:2002/C91:2005, Oil and liquid petroleum products, Laboratory density determination the isometric method.

24.DIXON, S. L., Fluid Mechanics, Thermodynamics of Turbo machinery, $4^{\text {th }}$ edition in SI/METRIC units, Butterworth-Heinemann, 1998.

25.MATTINGLY, J., Elements of Propulsion: Gas Turbines and Rockets, American Institute of Aeronautics and Astronautics, Reston, VA, USA, $2^{\text {nd }}$ edition, 2006.

$\overline{\text { Manuscript received: } 12.11 .2019}$ 